\title{
The Effect of Conflict Management Program on Quality of Patient Care
}

\author{
Ebtesam Saeed Ahmed Abd-EIrhaman, Aya Ghoneimy Hasanin Ghoneimy
}

Department of Nursing Administration, Benha University, Benha, Egypt

Email address:

foreversmilely@Yahoo.com (E. S. A. Abd-Elrhaman)

\section{To cite this article:}

Ebtesam Saeed Ahmed Abd-Elrhaman, Aya Ghoneimy Hasanin Ghoneimy. The Effect of Conflict Management Program on Quality of Patient Care. American Journal of Nursing Science. Vol. 7, No. 5, 2018, pp. 192-201. doi: 10.11648/j.ajns.20180705.16

Received: August 9, 2018; Accepted: September 19, 2018; Published: October 13, 2018

\begin{abstract}
Conflict in nursing profession is natural and inevitable and arises as a daily challenge in healthcare organizations. Therefore, conflict management is extremely important for organizational effectiveness and efficiency and nursing staff must effectively manage conflict in order to provide an environment that stimulates personal growth and ensures quality of patient care. Aim: The present study aimed to assess the effect of conflict management educational program for staff nurses on quality of patient care. Research Design: Quasi experimental design was utilized. Study Setting: The study was conducted in general Medical units at Benha University Hospital. The study sample was: All available staff nurses (116) and a convenient sample of (200) patients from the above mentioned study setting. Tools of data collection: Three tools were used: (1) conflict management knowledge questionnaire, (2) Rahim Organization Conflict Inventory II (ROCI II), subordinate form (B) and (3) quality of patients' care questionnaire. The result: The findings of this study showed that there was highly statistically significant improvement in staff nurses' knowledge regarding conflict thorough program. In addition, there was highly statistically significant improvement in conflict management strategies and level of quality of patient care thorough program. Conclusion: The study concluded that there was a positive highly statistical significant correlation between overall score of conflict management and quality of patient care thorough program. Recommendation: Hospital should carry out continuous inservice training program about policies and guidelines that facilitate collaborative practice and use a proactive measure to address conflict issues and moving toward resolution of it. And nursing faculties should to support nursing staff with required knowledge and skills that contribute to quality patient care.
\end{abstract}

Keywords: Conflict Management, Staff Nurses, Quality of Patient Care, ROCI II

\section{Introduction}

Today's competitions in the work environment and individual differences steadily increase conflict among staff. Conflict between nurses is considered a very important issue in the healthcare environment all over the world [1]. Additionally, conflict is one of the major challenges and depends primarily on the conflict management styles used so, all nurses, regardless of their position, must effectively manage conflict in order to ensure quality patient care $[2,3]$.

Conflict is defined as real or perceived differences between individuals with differing values, ideas or goals [4]. Also, it is a process that emerges when an individual feels forced and perceives blockage from the other and starts to resist it by opposing. It is a mental struggle resulting from unsuited or opposing needs, wishes or demands. These demands can be internal or external [5]. Conflict between nurses comes from many sources including disagreement over the appropriate work behavior or course of action, scarcity of important resources as money, materials, tools and supplies, individuals and group interdependence, differences in personality and tempers [6]. Furthermore, organizational change, ineffective communication, values and culture clashes, work policies and practices are considered common sources of conflict $[2,7]$.

There are several types of conflict such as intrapersonal, interpersonal, intra-group, inter-group, and organizational conflict. Intrapersonal conflict is discord or dissention within an individual, it occurs when one is facing with two or more incompatible demands. While interpersonal conflict occurs between two or more individuals, whose values, goals and beliefs are incompatible. Intra-group conflict occurs regularly 
within an established group, it may arise due to lack of support, new problem which necessitate changes within group member roles and relationships, imposed values and role inside the group. On the other hand, inter-group conflict arises between groups with differencing goals. And finally, organizational conflict occurs when there is discord between policies and procedures or informally accepted norms of behavior and patterns of communication $[3,6,8,9]$.

Conflict is a dynamic process that can be positive or negative, healthy or dysfunctional within work environment. Sometimes it can be creative. In some cases, it is essential to create conflict to bring justice in situation. It provides an opportunity to new system to shape better future. Thus, resolving conflict in an effective manner promotes good quality patient care. Unresolved conflicts may have several negative effects on patient outcomes $[5,10,11]$.

Conflict management is a process including the recognition of the conflict, determination of its intensity, evaluation of the effects of this intensity, determination of appropriate intervention methods and observation of their results $[11,12]$. There are five common strategies for conflict management as follows; avoiding, accommodating, competing, compromising and collaborating. These five strategies are identified by their location in two dimensions: concern for self and concern for other. The five styles thus represent different combination of assertiveness and cooperativeness [13-15].

Avoiding/or withdrawing (unassertive and uncooperative) is a lose-lose approach. This is passive style characterized by distancing from problems and hiding them. It is appropriate for trivial problems $[14,15]$. The second strategy is accommodating/or smoothing (unassertive and cooperative) which is a lose-win strategy. This may include sacrificing one's own needs or desires to end the conflict. It encourages people to express themselves. It is correct when the other parties are right or more powerful or the issue is more important to them $[14,16,17]$.

The third strategy is competing/or forcing (assertive and uncooperative). This style has a binary 'win-lose' outcome and involves high concern for self and low concern for others. Also, it uses force to solve the conflict among the parties involved. The overall effort is to win regardless of the cost. It is applicable when a quick or unpopular decision must be made $[11,12,14]$.

Compromising or negotiating (intermediate cooperative and assertive) is the fourth strategy in which each person gets something but provides something else up in the process, it means that someone wins and someone loses or both parties may lose something. It's generally a short-term solution unless conditions, positions or people change $[10,14,17$, 18]. Finally, collaborating (assertive and cooperative) is a win-win approach. It is the highest valued method of dealing with conflict as it is the only scenario in which both parties can win; however, it also requires trust in the other party. Both parties work together toward a common goal rather than framing the conflict as a win or lose scenario [12, 14, 16, 18].

Quality of care is a process that guarantee each patient the combination of diagnostic and therapeutic acts that will ensure the best result in terms of health based on current medical science at the lowest cost for the same result, with the lowest iatrogenic risk and for his greatest satisfaction in terms of procedures, results and human contact in the health care system. The concept of quality of care includes the dimensions of appropriateness "the care or services are appropriate to the needs of patient, patient group, or population", effectiveness "the care or services produce the desired outcomes for the patient" and efficiency "the maximum efficiency is achieved at the lowest cost" [19].

\subsection{Significance of the Study}

Conflict is present in all aspects of life and in all organizations, it is unavoidable and a natural part of all human relationships [11]. Today, all health-care organizations set goals and targets to improve the quality of patient care. Nurses are the main frontline personnel interacting with patients therefore, learning to resolve conflict is integral part to provide effective and efficient patient care and profit achievements [5, 34].

Additionally, mastering conflict management skills are crucial to maintain quality of patient care, improving staff moral and patient safety. Thus, successful healthcare organizations have to create a culture of mutual understanding and cooperation; in addition to equip their nursing staff with appropriate strategies to manage workplace conflict. However a limited budget make healthcare organizations unable to provide all necessary educational programs, so nursing faculties are responsible to support nursing staff with required knowledge and skills and contribute to quality patient care [20-22].

Moreover, from our clinical experience, it is observed that nurses facing many conflicting situations that negatively affect their efficiency in providing quality patient care. Helping those nurses to handle conflict effectively is important to sustain high quality patient care. So, this study was carried out to evaluate the effect conflict management program on quality of patient care.

\subsection{Aim of the Study}

This study was aimed to assess the effect of conflict management educational program for staff nurses on quality of patient care.

\subsection{Research Hypotheses}

(1) There will be significant improvement of staff nurses' knowledge and skills related to conflict management after implementation of educational program.

(2) Quality of patient care will be greatly improved after implementation of educational program for staff nurses than before.

(3) There will be a positive correlation between conflict management for staff nurses and quality of patient care after implementation of educational program. 


\section{Subjects and Methods}

\subsection{Research Design}

A quasi experimental design was utilized to achieve the aim of the present study

\subsection{Setting}

The study was conducted in general Medical units which include (6) units: medical unit 1 , medical unit 2 , medical unit 3 , medical unit 4 , medical unit 5 and medical unit 6 at Benha University Hospital.

\subsection{Subjects}

\subsubsection{Subject Type}

A convenient sample

\subsubsection{Subject Size}

All available staff nurses (116) and a convenient sample of (200) patients with inclusion criteria; the patient should be consciousness, educated, stay at least 3 days in the hospital, and not isolated from the above mention study setting at the time of study and agree to participate after clarification of purpose of the study.

\subsection{Tools of Data Collection}

Three tools were used to collect the data of this study:-

\subsubsection{Conflict Management Knowledge Questionnaire}

A structured questionnaire developed by the researchers based on the review of the related literature $[10-13,15]$. It consisted of two parts; part one: It included items related to personal characteristics of the staff nurses as (age, sex, department, qualification, marital status, and years of experience).

Part two: It was used to assess staff nurses' level of knowledge regarding conflict and conflict management strategies before program, immediate post program and three months follow up the program, including 25questions (true and false "15" questions and, multiple choice "10" questions).

\section{Scoring System}

Each question was scored "1" if it was correct and "zero" for the wrong answer. The scores of the items were summedup and then converted into a percent score. Knowledge was considered satisfactory if the percent score was $60 \%$ or more and unsatisfactory if the percent score was less than $60 \%$.

\subsubsection{Rahim Organizational Conflict Inventory-II (ROCI II), Subordinate form (B)}

This scale was developed by Rahim [18] to assess staff nurses' preferred conflict resolution strategies. ROCI II is self-assessment tool measure five dimensions or styles of handling conflict: collaborating, accommodating, competing, avoiding and compromising. It consisted of 28 items that includes "7" items for collaborating, "6" items for accommodating, "5" items for competing, "6" items for avoiding and "4" items for compromising.
Scoring system: using a five point Likert- scale ranging from $(1-5)$ strongly disagree $=(1)$, and (5) $=$ strongly agree. The score for each dimension in the ROCI II form is determined by summing specified items on the questionnaire.

\subsubsection{Quality of Patients' Care Questionnaire}

This tool was developed by Kim etal.[10] and modified by the researchers to measure important domains of the quality of care from a patient perspective. It consists of two parts; Part one: It consisted of items related to personal characteristics of the patient such as (age, sex, department, qualification, marital status, date of admission, times of hospital admission, and job).

Part two: It consisted of four domains namely; the art of treated patient (6 items); rationing of nursing care quality (12 items); health education quality (6 items) and continuity of nursing care (14 items).

Scoring System: using three point likert scale as following: never $=0$, sometimes $=1$, and always $=2$.the score of each dimension summed up converted in to percent score. Level of quality of patient care was considered high if the percent score more than $80 \%$, moderate $(60 \%-80 \%$ ) and low (less than $60 \%$ ).

\subsection{Methods}

\subsubsection{Tools Validity and Reliability}

The tools were reviewed by panel of expert of different nursing departments. The panel ascertained the face and content validity of the tools. The reliability was done by Cronbach's Alpha coefficient test. Cronbach's alphas were $(\mathrm{r}=0.94,0.96 \& 0.86)$ for conflict management knowledge questionnaire, the Rahim organization conflict inventory II (ROCI II), subordinate form (B) and quality of patients' care questionnaire respectively.

\subsubsection{Ethical Considerations}

Each staff nurse and patient were informed about the purpose and benefits of the study then oral consent was obtained before starting the data collection. Confidentiality was ensured throughout the study. The studied subjects were assured that all data were used only for research purpose and were informed of their rights to refuse or withdraw at any time of the study.

\subsubsection{Pilot Study}

A pilot study was carried out on $10 \%$ from the total number of sample (12) staff nurses and (20) patients to assess the tools clarity, objectivity and feasibility as well as to estimate the time needed for filling the tools. The pilot study was included in the main study sample.

\subsubsection{Educational Program About Conflict Management}

This program was designed to provide staff nurses an opportunity to develop conflict management knowledge and skill. It covered the following items; concept of conflict and conflict management, importance of studying conflict management, types and outcomes of conflict, causes of conflict, conflict process, contributing factors for effective 
conflict resolution, process of conflict resolution, conflict resolution strategies, factors affecting selection of conflict resolution strategies, conflict management plan and exercises of conflict resolution strategies.

\subsubsection{Field Work}

A written official letter was obtained from the dean of the Faculty of Nursing, Benha University and delivered to the director of Benha University Hospital in order to obtain their approval for conducting the study after explaining its purpose. The study was carried out for 10 months from at the beginning of April 2017 to the end of January 2018 as the following:

(1) The pre-intervention phase that took about two months from the beginning of April 2017 to the end of May 2017. The training strategy was developed based on the detected needs. As well, time schedule, teaching sessions, media included and the handout were prepared.

(2) The intervention phase was carried out from the beginning of June 2017 to end of August 2017. First staff nurses were grouped according to their units. The preprogram tests were fulfilled by the staff nurses before beginning of the training program. The conflict management knowledge questionnaire took from 2530 minutes to be completed and 15-20 minute for completing ROCI II. This pre-study test was designed to allow the researchers collect a baseline assessment of nurses' knowledge and skills in order to compare it with immediate post and follow-up program. Also, quality of patients' care questionnaire was fulfilled by the patients and took from 20-30 minutes to be completed before beginning of the training program. The data collected four days/week in the morning and afternoon shift.

After the questionnaires were completed, the training program was implemented by the researchers. The time plan of the program implemented over the period from the beginning of July 2017 to end of August 2017. The training program has taken 16 hours distributed as the following; 16 sessions, 1hour/session, 4days/week. Each researcher implemented the program with one group in the days by using available resources, relevant contents and instructional strategies for each session. Different methods of teaching were used such as lectures, group discussion and brainstorming. Instructional media included handout prepared by the researchers and distributed to all participants in the first day.

(3) The post-intervention phase (Evaluation Phase): In this phase, the effect of the strategy was evaluated; it was carried out immediately after the program implementation and after 3 months of intervention by using the same tools which were used before the program implementation. The time of the data collection lasted for five months from the beginning of September 2017 to end of January 2018.

\subsubsection{Statistical Analysis}

Data were collected, entered and analyzed by using SPSS (version 20) software computer package (special package for social science) and presented in tabular form. Descriptive statistics were applied (e.g. frequency, percentages, mean and standard deviation). Test of significance, chi-square "X2" , paired $\mathrm{t}$ test and correlation coefficient (r) were used. Statistically significant difference was considered at $\mathrm{p}$-value $\mathrm{p} \leq 0.05$.

\section{Results}

Table 1: Illustrated that more than one third of the studied nurses $(33.6 \%)$ had age from 25 to less than 30 years old with a mean age of $(34.4 \pm 7.1)$ years. As regarding to their social status, the most of them $(80.2 \%)$ were married. Concerning their qualification, more than three fifth of studied nurses $(61.2 \%)$ had nursing diploma. According to their units, $19.8 \%$ of them work in medical unit 3. As regarding to their years of experience, less than one third of them $(31.0 \%)$ had years of experience from 5 to 10 years and from15 years and more respectively with a mean years of experience $(14.3 \pm 7.3)$.

Table 1. Distribution of the studied nurses according to their personal characteristics $(N=116)$.

\begin{tabular}{|c|c|c|}
\hline Personal Characteristics & No & $\%$ \\
\hline \multicolumn{3}{|l|}{ Age (years) } \\
\hline $25<30$ & 39 & 33.6 \\
\hline $30<35$ & 30 & 25.9 \\
\hline $35<40$ & 15 & 12.9 \\
\hline$\geq 40$ & 32 & 27.6 \\
\hline $\mathrm{X}^{-} \pm \mathrm{SD}$ & $34.4 \pm 7.1$ & \\
\hline \multicolumn{3}{|l|}{ Social status } \\
\hline Married & 93 & 80.2 \\
\hline Un married & 23 & 19.8 \\
\hline \multicolumn{3}{|l|}{ Qualification } \\
\hline Nursing diploma & 71 & 61.2 \\
\hline Technical institute & 34 & 29.3 \\
\hline B.Sc. Nursing & 10 & 8.6 \\
\hline Master degree & 1 & .9 \\
\hline \multicolumn{3}{|l|}{ Unit } \\
\hline Medical unit 1 & 19 & 16.4 \\
\hline Medical unit 2 & 20 & 17.3 \\
\hline Medical unit 3 & 23 & 19.8 \\
\hline Medical unit 4 & 17 & 14.6 \\
\hline Medical unit 5 & 21 & 18.1 \\
\hline Medical unit 6 & 16 & 13.8 \\
\hline \multicolumn{3}{|l|}{ Years of experience } \\
\hline $1<5$ & 14 & 12.1 \\
\hline $5<10$ & 36 & 31.0 \\
\hline $10<15$ & 30 & 25.9 \\
\hline$\geq 15$ & 36 & 31.0 \\
\hline
\end{tabular}

Table 2: Clarified that $30.5 \%$ of the studied patients had age more than 50 years old with a mean age of $(45.19 \pm 0.75)$ years. While more than two thirds of them $(67.0 \%)$ were female. In relation to their social status, $70.2 \%$ of them were married. As for as to their qualification, about half of studied patients $(49.5 \%)$ read and write. According to length of stay in hospital, the majority of them $(86.0 \%)$ stayed from 3-5 
days in the hospital. As regarding to frequency of admission, the highest percent of them $(27.5 \%)$ admitted three times or more in medical unit 1.

Table 2. Distribution of the studied patients according to their personal characteristics $(N=200)$.

\begin{tabular}{|c|c|c|}
\hline Personal Characteristics & No & $\%$ \\
\hline \multicolumn{3}{|l|}{ Age (years) } \\
\hline$<30$ & 32 & 16.0 \\
\hline $30-40$ & 50 & 25.0 \\
\hline $40-50$ & 57 & 28.5 \\
\hline$>50$ & 61 & 30.5 \\
\hline $\mathrm{X}^{-} \pm \mathrm{SD}$ & $45.19 \pm 0.75$ & \\
\hline \multicolumn{3}{|l|}{ Sex } \\
\hline Male & 66 & 33.0 \\
\hline Female & 134 & 67.0 \\
\hline \multicolumn{3}{|l|}{ Social status } \\
\hline Married & 141 & 70.5 \\
\hline Un married & 59 & 29.5 \\
\hline \multicolumn{3}{|l|}{ Qualification } \\
\hline Read and write & 99 & 49.5 \\
\hline Secondary school & 71 & 35.5 \\
\hline University & 30 & 15.0 \\
\hline \multicolumn{3}{|l|}{ Length of stay in hospital } \\
\hline From 3-5 days & 172 & 86.0 \\
\hline More than 5 days & 28 & 14.0 \\
\hline $\mathrm{X}^{ \pm} \pm \mathrm{SD}$ & $1.14 \pm 0.35$ & \\
\hline \multicolumn{3}{|l|}{ Frequency of admission } \\
\hline Once & 41 & 20.5 \\
\hline Twice & 79 & 39.5 \\
\hline Three or more & 80 & 40.0 \\
\hline $\mathrm{X} \pm \mathrm{SD}$ & $1.14 \pm 0.35$ & \\
\hline \multicolumn{3}{|l|}{ Unit } \\
\hline Medical unit 1 & 55 & 27.5 \\
\hline Medical unit 2 & 26 & 13.0 \\
\hline Medical unit 3 & 26 & 13.0 \\
\hline Medical unit 4 & 27 & 13.5 \\
\hline Medical unit 5 & 32 & 16.0 \\
\hline Medical unit 6 & 34 & 17.0 \\
\hline
\end{tabular}

significant improvement in staff nurses' knowledge scores regarding conflict immediate post program $(87.3 \%)$ and three months follow up the program $(69.7 \%)$ than preprogram scores.

Table 3: Revealed that there was highly statistically significant improvement of mean and standard deviation for conflict management strategies immediate post program and three months follow up program than preprogram scores as reported by staff nurses. As regarding preprogram, highest score represent avoiding and competing strategy while collaborating and accommodating strategy during immediate post program and finally, follow up program includes collaborating and avoiding strategy.

Table 4: Portrayed that there was positive statistically significant correlation between conflict management strategies immediate post program and personal characteristics for studied nurses.

Table 5: Revealed that there was highly statistically significant improvement in the level of quality of patient care immediate post program and three months follow up program than preprogram scores as reported by studied patients.

Figure 2: Clarified that there was highly statistically significant improvement in total level quality of patient care immediate post program (80.0\%) and three months follow up the program $(62.0 \%)$ than preprogram for studied patients.

Table 6: Showed that there was a positive statistically significant correlation between quality of patient care immediate post program and personal characteristics for studied patients.

Table 7: Illustrated that there was a positive highly statistical significant correlation between overall score of conflict management and quality of patient care thorough program.

Figure 3: Showed that there was highly statistically

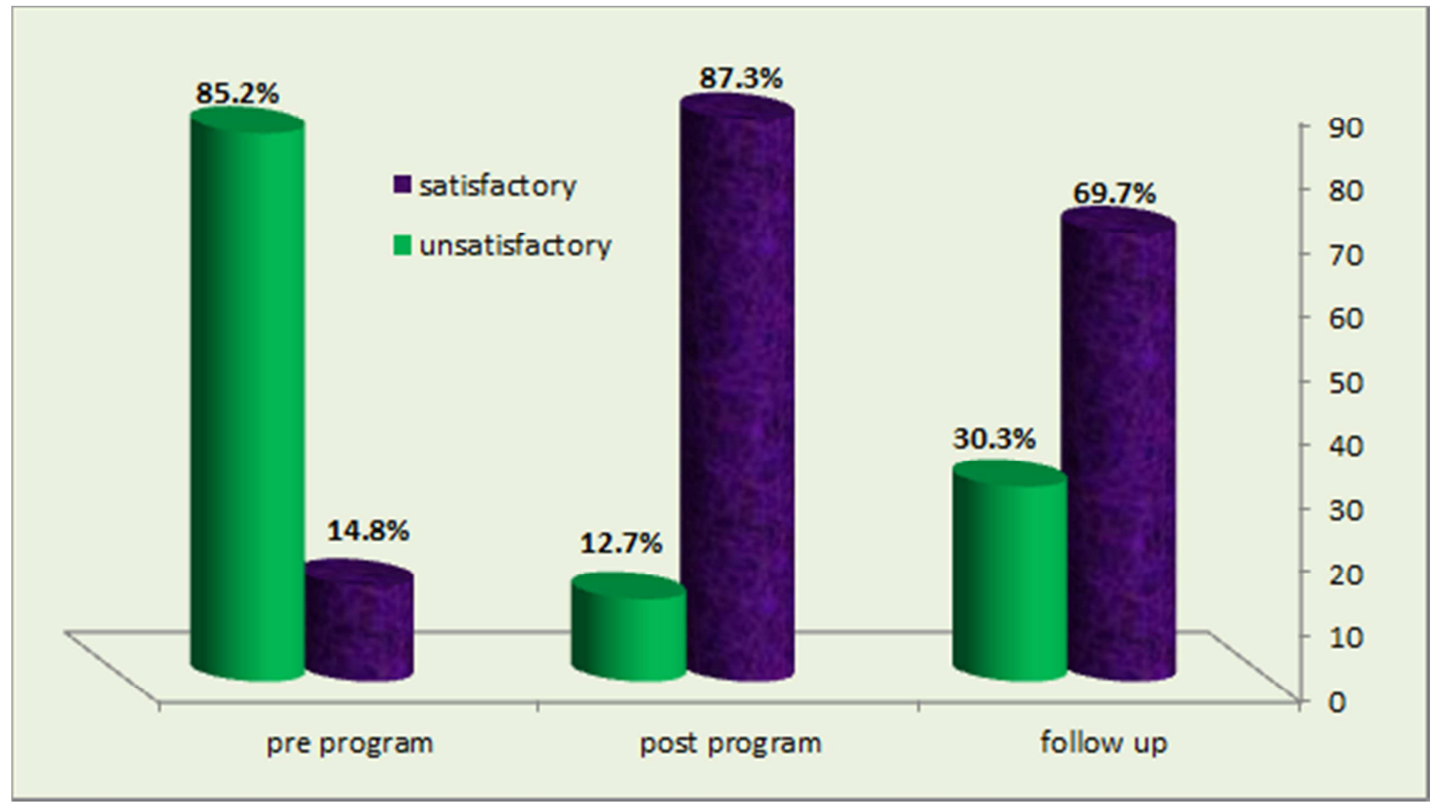

Figure 1. Level of studied nurses knowledge about conflict thorough program $(n=116)$. 
Table 3. Mean and standard deviation of conflict management strategies among studied nurses thorough program ( $n=116)$.

\begin{tabular}{|c|c|c|c|c|c|c|c|c|}
\hline $\begin{array}{l}\text { Conflict management } \\
\text { strategies }\end{array}$ & $\begin{array}{l}\text { Max } \\
\text { score }\end{array}$ & $\begin{array}{l}\text { Pre program } \\
\text { Mean } \pm \text { SD }\end{array}$ & $\begin{array}{l}\text { Post program } \\
\text { Mean } \pm \text { SD } \\
\end{array}$ & $\begin{array}{l}\text { Follow up program } \\
\text { Mean } \pm \text { SD }\end{array}$ & Paired t-test 1 & P Value & Paired t-test 2 & P Value \\
\hline Collaborating & 14 & $2.00 \pm 0.92$ & $21.98 \pm 1.00$ & $10.70 \pm 1.34$ & \multirow{6}{*}{48.94} & \multirow{6}{*}{$<0.001 * *$} & \multirow{6}{*}{46.58} & \multirow{6}{*}{$<0.001 * *$} \\
\hline Accommodating & 12 & $1.80 \pm 0.83$ & $8.19 \pm 1.79$ & $7.55 \pm 2.20$ & & & & \\
\hline Competing & 10 & $6.36 \pm 1.89$ & $7.36 \pm 1.46$ & $6.84 \pm 1.77$ & & & & \\
\hline Avoiding & 12 & $8.34 \pm 1.95$ & $7.00 \pm 2.52$ & $8.01 \pm 2.05$ & & & & \\
\hline Compromising & 8 & $1.21 \pm 0.47$ & $3.32 \pm 1.67$ & $3.62 \pm 1.47$ & & & & \\
\hline Total & 56 & $19.73 \pm 3.99$ & $36.97 \pm 5.72$ & $36.75 \pm 6.48$ & & & & \\
\hline
\end{tabular}

**A high statistical significant difference $(\mathrm{P} \leq 0.001)$

Paired t-test 1: pre \& post

Paired t-test 2: pre \& follow up

Table 4. Correlation between conflict management strategies and personal characteristics of studied nurses $(n=116)$.

\begin{tabular}{|c|c|c|c|c|c|c|}
\hline \multirow{3}{*}{ Elements } & \multicolumn{6}{|c|}{ Personal characteristics } \\
\hline & \multicolumn{2}{|c|}{ Experience } & \multicolumn{2}{|l|}{ Age } & \multicolumn{2}{|c|}{ Qualification } \\
\hline & $\mathbf{R}$ & P-value & $\mathbf{r}$ & P-value & $\mathbf{r}$ & P-value \\
\hline conflict management immediate post program & 0.554 & $<0.001 * *$ & 0.381 & $<0.001^{* *}$ & 0.595 & $<0.001 * *$ \\
\hline
\end{tabular}

**A high statistical significant difference $(\mathrm{P} \leq 0.001)$

Table 5. Distribution the quality of patient care dimension for studied patients thorough program $(n=200)$.

\begin{tabular}{|c|c|c|c|c|c|c|c|c|}
\hline \multirow{3}{*}{ Quality of patient care domains } & \multicolumn{6}{|c|}{ Patients $(n=200)$} & \multirow{3}{*}{$\mathbf{X}^{2}$} & \multirow{3}{*}{ P-Value } \\
\hline & \multicolumn{2}{|c|}{ Pre-program } & \multicolumn{2}{|c|}{ Post-program } & \multicolumn{2}{|c|}{ Follow up-program } & & \\
\hline & No & $\%$ & No & $\%$ & No & $\%$ & & \\
\hline \multicolumn{9}{|l|}{ The art of treated patient: } \\
\hline High & 10 & 5.0 & 178 & 89.0 & 153 & 76.5 & \multirow{3}{*}{1138.22} & \multirow{3}{*}{$<0.001 * *$} \\
\hline Moderate & 40 & 20.0 & 10 & 5.0 & 31 & 15.5 & & \\
\hline Low & 150 & 75.0 & 12 & 6.0 & 16 & 8.0 & & \\
\hline \multicolumn{7}{|l|}{ - Rationing of nursing care quality } & \multirow{4}{*}{1165.59} & \multirow{4}{*}{$<0.001 * *$} \\
\hline High & 4 & 2.0 & 148 & 74.0 & 133 & 66.5 & & \\
\hline Moderate & 16 & 8.0 & 23 & 11.5 & 43 & 21.5 & & \\
\hline Low & 180 & 90.0 & 29 & 14.5 & 24 & 12.0 & & \\
\hline \multicolumn{7}{|l|}{ Health education quality: } & \multirow{4}{*}{1200.00} & \multirow{4}{*}{$<0.001 * *$} \\
\hline High & 1 & 0.5 & 143 & 71.5 & 129 & 64.5 & & \\
\hline Moderate & 8 & 4.0 & 41 & 20.5 & 52 & 26.0 & & \\
\hline Low & 191 & 95.5 & 16 & 8.0 & 19 & 9.5 & & \\
\hline \multicolumn{7}{|l|}{ Continuity of nursing care: } & \multirow{4}{*}{1178.74} & \multirow{4}{*}{$<0.001 * *$} \\
\hline High & 0 & 0.0 & 137 & 68.5 & 119 & 59.5 & & \\
\hline Moderate & 4 & 2.0 & 27 & 13.5 & 31 & 12.5 & & \\
\hline Low & 196 & 98.0 & 36 & 18.0 & 50 & 25.0 & & \\
\hline
\end{tabular}

$* *$ A high statistical significant difference $(\mathrm{P} \leq 0.001)$

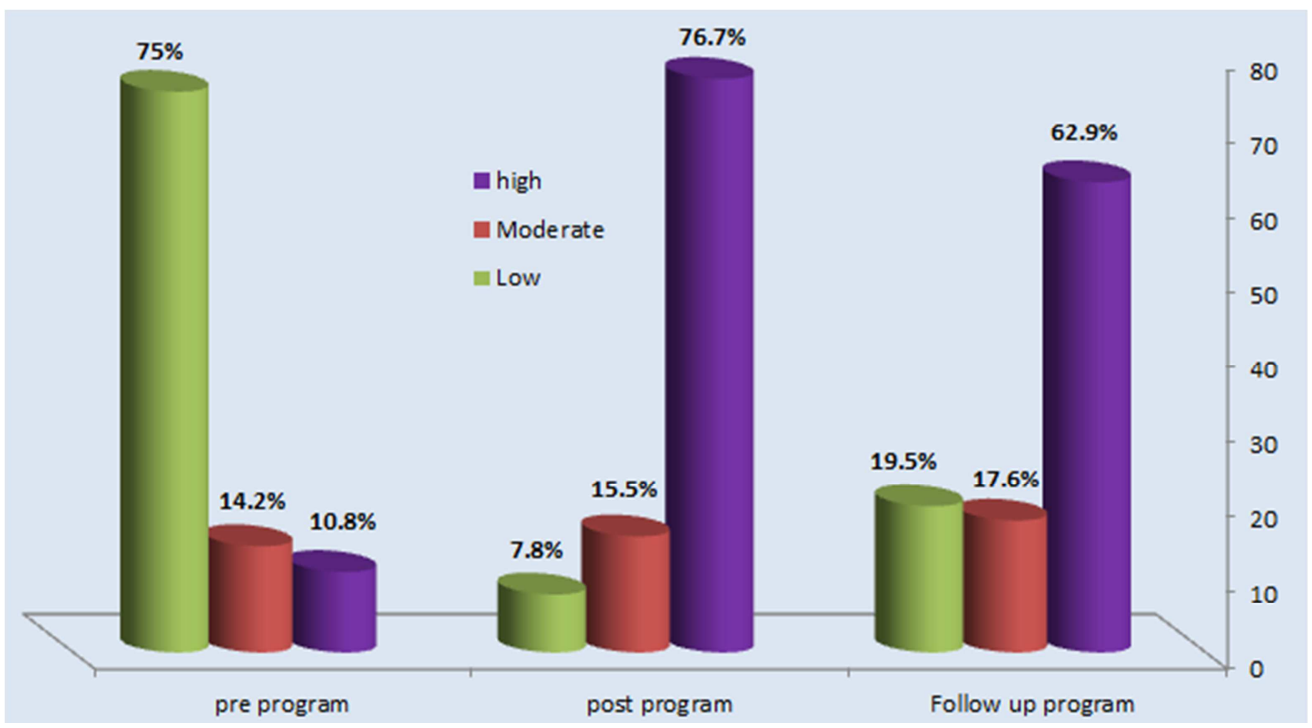

Figure 2. Total level of the quality of patient care as reported by studied patients' thorough program $(n=200)$. 
Table 6. Correlation between personal characteristics and quality of patient care $(n=200)$.

\begin{tabular}{|c|c|c|c|c|c|c|c|c|}
\hline \multirow{3}{*}{ Items } & \multicolumn{8}{|c|}{ Personal characteristics for studied patients } \\
\hline & \multicolumn{2}{|c|}{ Qualification } & \multicolumn{2}{|c|}{ Length of stay in hospital } & \multicolumn{2}{|c|}{ Frequency of admitted } & \multicolumn{2}{|l|}{ Age } \\
\hline & $\mathbf{r}$ & P-value & $\mathbf{r}$ & P-value & $\mathbf{r}$ & P-value & $\mathbf{r}$ & P-value \\
\hline Quality of patient care immediate post program & 0.553 & $<0.001 * *$ & 0.425 & $<0.001 * *$ & 0.331 & $<0.001 * *$ & 0.518 & $<0.001 * *$ \\
\hline
\end{tabular}

**A high statistical significant difference $(\mathrm{P} \leq 0.001)$

Table 7. Correlation between overall score of conflict management and quality of patient care thorough program ( $n=200)$.

\begin{tabular}{lll}
\hline \multirow{2}{*}{ Parameters } & \multicolumn{2}{l}{ Overall score for quality of patient care } \\
\cline { 2 - 3 } & $\mathbf{R}$ & p-value \\
\hline Overall score of the conflict management & 0.283 & $<0.001^{* *}$ \\
\hline
\end{tabular}

**A high statistical significant difference $(\mathrm{P} \leq 0.001)$

\section{Discussion}

Conflict emerges from variety of sources including interpersonal differences in age, experience, opinions and values, errors in communication, lack of work justice, unclear job description, expectations and policies. In addition, the nature of work environment including work interdependence and physician dominance, limited resources, work overload and nursing shortage can also contribute to conflict. Conflict management and communication skills are crucial to maintain quality of patient care, improving staff moral and patient safety. So, successful healthcare organizations have to create a culture of mutual understanding and cooperation; in addition to equip their nursing staff with appropriate strategies to manage workplace conflict [19].

The result of present study indicated that more than one third of the studied nurses had age from 25 to less than 30 years old with a mean age of $(34.4 \pm 7.1)$ years. As regarding to their social status, the most of them $(80.2 \%)$ were married. Concerning their qualification, more than three fifth of studied nurses had nursing diploma. According to their units, $19.8 \%$ of them work in medical unit 3 . As regarding to their years of experience, less than one third of them had years of experience from 5 to 10 years and from $15 y$ years and more respectively with a mean years of experience (14.3 \pm 7.3 ).

These results were in disagreement with Ahmed and Obied [23] who conducted a study entitled "Effect of Utilizing Conflict Management Strategies for ICU Nurses on Patient Care" and reported that the majority of the nurses were in the age group between 20 up to 29 years and almost half of them fall in the same age group. Around two thirds of the studied nurses held a bachelor degree. The highest percentages of nurses working in medical ICU were single and had years of experience from 1 to less than

The result of present study revealed that $30.5 \%$ of the studied patients had age more than 50 years old with a mean age of $(45.19 \pm 0.75)$ years. While more than two thirds of them were female. In relation to their social status, $70.2 \%$ of them were married. As for as to their qualification, about half of studied patients read and write. According to length of stay in hospital, the majority of them stayed from 3-5 days in the hospital. As regarding to frequency of admission, the highest percent of them admitted three times or more in medical unit
1. While Ballah [24] reported that more than one quarter of patients had age less than 40 years old and the highest percentage of them were female, married, illiterate and admitted to the hospital for the first time.

Concerning nurses' knowledge about conflict, the result of present study revealed that there was highly statistically significant improvement in staff nurses' knowledge scores regarding conflict immediate post program and three months follow up the program compared to preprogram. This might be attributed to the ability of the nurses to gain knowledge easily and they were interested in the research topic. In Addition, the program was successful and increased their knowledge. This result was supported by Ahmed and Obied [23] who found that there was improvement in nurses' knowledge in areas related to causes, definition of conflict, conflict management strategies and consequences of conflict post-intervention compared with pre- educational program.

In the same line, Said Ahmed \& El Demerdash [25] who conducted a study entitled "An Educational Program about Nursing Managers' Transformational Leadership, Conflict Management Styles and Decision Making Effectiveness" reported that the levels of nursing managers' total knowledge regarding transformational leadership and conflict management were significantly improved post-educational program. Also Ibrahim et al. [26] who conducted a study entitled "The Effect of Conflict-Management Enhancing Strategy for Head Nurses on the Quality of Vertical Dyad Linkage with Nurses" stated that there was a statistically significant improvement in head nurses' knowledge regarding conflict and its management strategies after strategy implementation.

Regarding conflict management among nurses, the result of present study revealed that there was highly statistically significant improvement of mean and standard deviation for conflict management strategies immediate post program and three months follow up program than preprogram scores as reported by staff nurses. As regarding preprogram, the highest score represent avoiding and competing strategy while collaborating and accommodating strategy during immediate post program and finally, follow up program included collaborating and avoiding strategy. This might be due to conflict management program was effective and nurses learned how to deal with different situation and problems and how to face and manage conflict either in the 
work place or outside. Additionally, they learned to work together toward a common goal rather than framing the conflict as a win or lose scenario. While preprogram, nurses were trying to avoid any problems leading to conflict and to win with low concern for the other party.

While Ahmed and Obied [23] found that around one third of medical and cardiac ICU nurses preferred avoiding style followed by compromising pre-intervention. and more than one third of nurses preferred collaboration style followed by accommodation style post-intervention. While Ibrahim et al. [26] reported that, in the pre-training stage, it was found that more than two-thirds of the studied head nurses used accommodating strategy as a primary method to resolve conflict followed by compromising strategy. Meanwhile, in the post implementation stage, $45.2 \%$ of the studied head nurses used accommodating strategy as a primary method to resolve conflict followed by $9.7 \%$ of them used avoiding and compromising strategies to resolve conflict.

This result was inconsistent with Al-Hamdan et al. [27] Who conducted a study entitled" Conflict management styles used by nurse managers in the Sultanate of Oman" and reported that Nurse managers in Oman used all five conflict management styles with integrating style as the first choice followed in order by compromising, obliging, dominating and avoiding. Also, Nussera et al. [28] who conducted a study entitled" Conflict Management Style of Jordanian Nurse Managers and its Relationship to Staff Nurses' Intent to Stay" found that an integrative style was the first choice for nurse managers and the last choice was a dominating style.

As regard to correlation between conflict management strategies and personal characteristics of studied nurses, the result of present study revealed that there was positive statistically significant correlation between conflict management strategies immediate post program and personal characteristics (experience, age and qualification) of the studied nurses. This might be due to with increase in age, having experience and high education, the ability of the person to face situations and problems and how to cope with conflict increase accordingly.

This result was consistent with Baddar et al. [29] who conducted a study entitled " Conflict Resolution Strategies of Nurses in A Selected Government Tertiary Hospital in the Kingdom of Saudi Arabia" and indicated that there was no significant difference relation between nurses' use of conflict resolution strategies with patients and doctors and their socio-demographic variables (age and years of nursing experience) except nursing qualification.

On the other hand, this result was in disagreement with Polat et al. [30] who conducted a study about " The Management Strategies used for Conflicts Resolution: A Study on the Chief Physician and the Directors of Health Care Services" and found that there was no relationship between conflict resolution strategies of the administrators and their age, the tenure of their task and occupation. Also, Anthony et al. [31] who conducted a study entitled" Conflict management styles used by nurses in Jordan" reported that no statistically significant relationship was found for any of conflict management strategies in relation to age and years of experience. Additionally, there was no statistically significant difference for any of the conflict management styles in relation to nursing education.

In relation to level of quality of patient care, the result of present study revealed that there was highly statistically significant improvement in the level of quality of patient care immediate post program and three months follow up program than preprogram scores as reported by studied patients. This could be attributed to conflict management program was successful and helped nurses how to handle conflict effectively in work place and this accordingly improved the quality patient care.

These findings were supported by Ahmed and Obied [23] who found that Educational program was beneficial for improving ICU nurses' knowledge and practice to manage conflict. Pre-educational program, majority of the studied nurses accepted workplace conflict that negatively affected their patient care but post-intervention, there were improvement regarding their patient care quality. Also, Sinha [32] confirmed that it is important for hospital leaders and health care providers to work together to develop strategies to manage conflict and improve collaborative relationship among healthcare professionals in order to indirectly enhance the quality of patient care.

Concerning correlation between quality of patient care and personal characteristics, the result of present study revealed that there was positive statistically significant correlation between quality of patient care immediate post program and personal characteristics for studied patients (qualification, length of stay in hospital, age and frequency of admitted). This could be attributed to when patients are adult, highly educated and enter hospital many times for not less than three days, this help them to understand and evaluate what type and quality of care given .

This result was in agreement with Kvist et al. [33] who found that patients' perceptions of overall quality of care were positively related to general job satisfaction of nursing staff. Adequate numbers of staff appeared to be the clearest aspect affecting quality of care. Older patients were more satisfied with staff number than younger patients.

Finally, the result of present study revealed that there was a positive highly statistical significant correlation between overall score of conflict management and quality of patient care thorough program. This finding was supported by Anthony et al. [31] who stated that conflict can affect patient care if handled badly. Poorly handled conflict results in lower staff morale and poorer retention, both adversely affect patient care. In the same line, Ahmed and Obied [23] reported that there was positive correlation between patient care and nurses' preference of conflict management style.

\section{Recommendation}

The findings of the study suggest that:

(1) Nursing faculties should support nursing staff with 
required knowledge and skills that contribute to quality patient care

(2) Hospital should carry out continuous in-service training program about policies and guidelines that facilitate collaborative practice and use a proactive measure to address conflict issues and moving toward resolution of it.

(3) The management and the subordinates must be concerned and devoted to resolving conflict among coworkers by being willing to listen and to find accurate solutions.

(4) Hospital should provide internal and/or external third party assistance (e.g. spiritual care, ethicists, safe workplace advocate and professional practice specialists/consultants) to offer productive support and manage/mitigate conflict.

(5) Hospital should implement a regular assessment, which may include quality indicators, to identify the types and outcomes (short-term and long-term) of conflict among nurses, physicians and other health-care professionals.

(6) Further studies should be conducted for exploration on conflict management abilities and skills among undergraduate and graduate students.

\section{Conclusions}

There was a positive highly statistical significant correlation between overall score of conflict management and quality of patient care thorough program $(\mathrm{r}=0.283$, $\mathrm{p}<0.001)$. There was positive statistically significant correlation between conflict management strategies immediate post program and personal characteristics for studied nurses. In addition, there was a positive statistically significant correlation between quality of patient care immediate post program and Personal characteristics for studied patients.

\section{Acknowledgements}

The researchers would like to express gratitude and appreciations to (116) staff nurses and (200) patients who participated in this study for their effective cooperation.

\section{References}

[1] Dahlkemper, T. Nursing Leadership, Management, and Professional Practice for the LPN/LVN, 2017: 6th ed., F.A. Davis Company.

[2] Ellis, P. \& Abbott, J. Strategies for managing conflict within the team. Journal of Renal Nursing. (ISSN 2041-1448). 2011: 3(1) 40 - 43. http://dx.doi.org/10.12968/jorn.2011.3.1.40.

[3] Yoder-Wise, P. Leading and managing in nursing. Elsevier Health Sciences. 2015.

[4] Ledlow, G. and Stephens, J. Leadership for Health Professionals. Jones \& Bartlett Learning. 2018.
[5] Murray, E. Nursing leadership and management: for patient safety and quality care, F.A. Davis Company. 2018.

[6] Cherry B, Jacob SR. Contemporary nursing: Issues, trends, \& Management, Mosby. 2017.

[7] Reece, B. and Reece, M. Effective human relations: interpersonal and organizational applications, Cengage Learning. 2017.

[8] Chang E, Daly J. Transitions in Nursing: Preparing for Professional Practice, Elsevier - Health Sciences Division. 2016.

[9] Higazee, M., and Zeinhom ,A. Types and levels of conflicts experienced by nurses in the hospital settings. Health Science Journal. 2015: Available from: http://www.hsj.gr/medicine/types-and-levels-of-conflicts-experienced-by-nurses-inthe-hospital-set tings.php?aid $=7838$.

[10] Kim, W., Nicotera, A. and McNulty, J. Nurses' perceptions of conflict as construc-tive or destructive. Journal of Advanced Nursing , 2015: 71(9), Pp 2073 - 2083, Available @ CINAHL, EBSCOhost Academic Search Elite, Accessed 28.03.

[11] Marquis, B. and Huston, C. Leadership Roles and Management Functions in Nursing: Theory and Application. 2015: from:https://books. google. com.eg/books? Id.

[12] Rudani, R. Principles of management [internet]. McGraw-Hill education (India); 2013. Available from:https://books.google.com. eg/books ?id.

[13] Huber, D. Leadership and Nursing Care Management, 2014: 5th ed. Elsevier Health Sciences.

[14] Obied H., Shabaan F., Shalaby H., and Gadiry S. Application of designed orientation program for nurse interns based on learning needs assessment, Journal of American Science, 2013: 9 (3), PP 80-91.

[15] Roussel, L. Management and Leadership for Nurse Administrators [Internet]. Jones \& Bartlett Learning. 2013: from: https://books. Google .com .eg/books?

[16] Abudahi, A. Relationship between perceived organizational climate and conflict management strategies among nurses in Cairo University Hospital: Piloting a conflict management approach, 2012 (Unpublished Doctorate thesis), Cairo University, Egypt.

[17] Turgut, E. Demİrkol, H., Türk, M., Cİrİt, N. and Bilge, A. The effectiveness of the conflict management education on staff in a mental health hospital. Int Ref J Nurs Res; 2017; 1(9).

[18] Rahim, M. A. Managing conflict in organizations, 2011; 4th ed., New Jersey: Transaction Publishers, ISBN 978-1-41281456-0.

[19] Dahshan, M. and Keshk, L. Managers' Conflict Management Styles and its Effect on Staff Nursese ${ }^{\text {ee }}$ Turnover Intention at Shebin El Kom Hospitals, Menoufiya Governorate, World Journal of Medical Sciences, 2014; 11 (1),PP 132-143.

[20] Johansen, M. Keeping the peace: Conflict management strategies for nurse managers, Nursing Management. 2012, February.50-54Lippincott Williams \& Wilkins .Www .nursing management. Com.

[21] Radford, J. Assessing conflict management style of educational leaders as a means to improve relationships and effectiveness. 2013. 
[22] Riley, P., Zuber.A.,Vindigni,S., Gupta, N., Verani, A., Sunderland, N., and Campbell, J. Information systems on human resources for health: a global review, Hum Resour Health, 2012; 10(7), PP 10-1186.

[23] Ahmed, S. and Obied, H. Effect of utilizing conflict management strategies for icu nurses on patient care, Journal of Nursing and Health Science, 2016: 5(2), PP 39-46.

[24] Ballah, H. Relationship between nursing care delivery system and patient satisfaction, Master thesis , Faculty of nursing, Benha University, 2018: pp 45-46.

[25] Said Ahmed, R. and El Demerdash, S. An educational program about nursing managers` transformational leadership, conflict management styles and decision making effectiveness , Journal of Nursing and Health Science, 2014; 3(3),PP 42-56.

[26] Ibrahim, S. Mohamed, H. and EL-Gazar, H. The Effect of Conflict-Management Enhancing Strategy for Head Nurses on the Quality of Vertical Dyad Linkage with Nurses, International Journal of Nursing Didactics, 2018; 8(04), PP 25-34.

[27] Al-Hamdan, Z., Shukri, R. and Anthony, D. Conflict management styles used by nurse managers in the Sultanate of Oman, Journal of Clinical Nursing, 2011; 20, PP 571-580.

[28] Nussera, H, Al-Hamdan, Z. and Masa'deh, R. Conflict management style of Jordanian nurse managers and its relationship to staff nurses' intent to stay, Journal of Nursing Management, 2016;24, PP 137-145.

[29] Baddar, F., Salem, O. and Villagracia,H. Conflict resolution strategies of nurses in a selected government tertiary hospital in the Kingdom of Saudi Arabia, Journal of Nursing Education and Practice, 2016; 6(5), PP 91-99.

[30] Polat,S., Sen, H., Ünald,N., Sakarya,S. and Yıldırım, T. The management strategies used for conflicts resolution: A study on the chief physician and the directors of health care services, International Journal of Medical Research \& Health Sciences, 2017; 6(8), PP 105-110.

[31] Anthony, D, Norrie, P and Al-Hamdan, Z. Conflict management styles used by nurses in Jordan, Journal of Research in Nursing, 2014; 19 (1). PP 40 - 53.

[32] Sinha, A. the role of team effectiveness in quality of health care, 2017: available @ http://www.imedpub.com/articles/therole-of-team-effectiveness-in-quality-ofhealthcare.php?aid=18179.

[33] Kvist, K.,Voutilainen, A. , Mäntynen ,R. and Vehviläinen, K. The relationship between patients' perceptions of care quality and three factors: nursing staff job satisfaction, organizational characteristics and patient age, 2014;14, P.466.

[34] Patton, C. Conflict in Health Care: A literature review, the internet journal of healthcare administration, 2014; 9 (1), Available from: http://ispub.com/IJHCA/9/1/20081. 